\title{
Pengukuran Kualitas Aplikasi Rekap Indikator Mutu Harian RS Bhayangkara Jambi Menggunakan Metode McCall
}

\author{
$\underline{\text { Ari Andrianti }}$ \\ Sistem Informasi, Fakultas Ilmu Komputer, Universitas Dinamika Bangsa \\ Jalan Jendral Sudirman Thehok, Jambi, Indonesia \\ E-mail: ariandrianti@gmail.com
}

\begin{abstract}
Bhayangkara Jambi Hospital in implementing quality improvement and patient safety programs is need an application that performs the process of recapitulating the daily quality indicators msut to do by all units in the hospital. Applications that have been made and running have very important function in the daily hospital quality recording process to prevent failure in use is need to measure several quality factors. This study aims to measure the quality of the application of the daily quality indicator recap Bhayangkara Jambi Hospital based on user perceptions using the McCall method. Data collection is do by distributing questionnaires. Data analysis is use quantitative data analysis. Quality measurement of the daily quality indicator recap application of Bhayangkara Jambi Hospital is using McCall quality factors that is correctness, reliability, efficiency and usability to determine the quality and level of utilization of current quality indicator application recap users, the feasibility results obtained by the user stated that it is very feasible to use.
\end{abstract}

Keywords: Quality Indicator, Application, McCall Factor Model

\begin{abstract}
Abstrak
Rumah Sakit Bhayangkara Jambi dalam melaksanakan program peningkatan mutu dan keselamatan pasien memerlukan sebuah aplikasi yang melakukan proses rekapitulasi terhadap indikator mutu harian yang dilakukan oleh semua unit yang ada di rumah sakit. Aplikasi yang telah dibuat dan berjalan saat ini memiliki fungsi yang sangat penting dalam proses pencatatan mutu harian rumah sakit untuk mencegah terjadi kegagalan dalam penggunaannya perlu dilakukan pengukuran terhadap beberapa faktor kualitas dari aplikasi tersebut. Penelitian ini bertujuan untuk mengukur kualitas aplikasi rekap indikator mutu harian RS Bhayangkara Jambi berdasarkan persepsi pengguna dengan menggunakan metode McCall. Pengumpulan data dilakukan dengan pembagian kuesioner. Analisis data menggunakan analisis data kuantitatif. Pengukuran kualitas terhadap aplikasi rekap indikator mutu harian RS Bhayangkara Jambi dengan menggunakan faktor kualitas McCall yaitu kebenaran, kehandalan, efisiensi dan kegunaan untuk mengetahui sejauh mana kualitas dan tingkat pemanfaatan pengguna aplikasi rekap indikator mutu saat ini, diperoleh hasil kelayakan oleh pengguna menyatakan sangat layak untuk digunakan.
\end{abstract}

Kata kunci: Indikator Mutu, Aplikasi, Model Faktor McCall

\section{Pendahuluan}

Rumah Sakit Bhayangkara Jambi sebagai salah satu rumah sakit milik pemerintah yang memberikan pelayanan kesehatan kepada masyarakat umum dalam hal ini dibawah kendali Institusi POLRI telah menetapkan indikator mutu yang harus dipenuhi oleh semua unit yang ada. Untuk melaksanakan program peningkatan mutu dan keselamatan pasien tersebut rumah sakit perlu menetapkan tujuan dan mengetahui seberapa baik proses kerja dilaksanakan dan divalidasi datanya hal ini dapat dilakukan dengan adanya aplikasi rekap indikator mutu harian. Aplikasi ini menyediakan laporan rekapitulasi harian untuk indikator mutu yang sudah dilaksanakan oleh semua unit yang ada di RS Bhayangkara Jambi. Aplikasi yang telah dibuat dan berjalan tersebut memiliki fungsi yang sangat penting dalam proses pencatatan mutu harian rumah sakit untuk mencegah terjadinya kegagalan dalam penggunaanya perlu dilakukan pengukuran terhadap beberapa faktor kualitas untuk menemukan kelemahan dan perbaikan kedepannya.

Pengukuran perangkat lunak merupakan hal yang penting karena dengan dilakukannya pengukuran maka kualitas suatu sistem informasi akan diketahui. Salah satu metode pengukuran adalah pengukuran berdasarkan teori kualitas McCall. Menurut kaidah McCall, cara mengukur kualitas atribut tersusun secara hirarkis, dimana level atas (high-level attribute) disebut faktor (factor), dan level bawah (low-level attribute) disebut dengan kriteria (criteria). Faktor menunjukkan atribut kualitas produk dilihat dari sudut 
pandang pengguna. Sedangkan kriteria adalah parameter kualitas produk dilihat dari sudut pandang perangkat lunaknya sendiri. Faktor dan kriteria ini memiliki hubungan sebab akibat (cause-effect)[1].

Kualitas perangkat lunak dapat diartikan sebagai proses yang efektif yang diwujudkan dalam bentuk produk yang dapat memberikan manfaat dan dapat diukur. Pengukuran kualitas suatu sistem informasi sangatlah penting untuk mengetahui bagaimana kondisi terkini dari sistem informasi itu sendiri, apakah masih relevan ataukah tidak dengan kondisi terkini, apabila setelah dilakukan pengukuran ternyata sistem informasi tersebut sudah tidak relevan maka dapat dijadikan acuan ataupun rujukan untuk diadakan perbaikan agar lebih baik lagi [2].

Oleh sebab itu, perlu dilakukan pengukuran aplikasi rekap indikator mutu harian di RS Bhayangkara Jambi dengan metode McCall. Hasil penelitian yang berupa persentase kualitas aplikasi rekap indikator mutu harian RS Bhayangkara Jambi berdasarkan persepsi pengguna menggunakan metode McCall ini diharapkan dapat memberikan manfaat berupa informasi untuk mengetahui tingkat kualitas perangkat lunak, sehingga dapat menjadi masukan dan saran bagi institusi dalam perbaikan sistem kedepannya untuk meningkatkan pemanfaatan pengguna sesuai dengan yang diharapkan.

Penelitian terdahulu tentang uji kelayakan Sistem Informasi Akademik sangat diperlukan untuk mengetahui akan kekurangan dan kesalahan yang terdapat pada aplikasi. Sehingga dari hasil pengujian nantinya bisa dilakukan perbaikan untuk menghasilkan sistem informasi akademik yang lebih baik dan berkualitas. Hasil penilaian yang diberikan oleh para responden terhadap sistem informasi akademik diperoleh nilai terendah 60,9 dan nilai tertinggi 77,5. Nilai rata-rata keseluruhan dari responden sebesar 68,02 dengan kategori cukup baik [3].

Penelitian lainnya melakukan uji kelayakan Sistem Informasi Unit Kesehatan Sekolah Berbasis Website di SMK Muhammadiyah 1 Bantul dengan Faktor Kualitas McCall, data penelitian ini diperoleh dari hasil pengisian seperangkat instrument berupa kuesioner yang diberikan kepada sejumlah responden untuk menilai hasil kelayakan dari perangkat lunak yang dikembangkan. Berdasarkan hasil analisis terhadap Sistem Informasi Unit Kesehatan Sekolah Berbasis Website di SMK Muhammadiyah 1 Bantul diperoleh hasil kelayakan dari indicator Correctness sebesar 78\% dengan kategori layak, dari indicator Reliability diperoleh persentase $78 \%$ dengan kategori layak, dari indicator efficiency diperoleh persentase sebesar $76 \%$ dengan kategori layak, dari indicator integrity diperoleh persentase sebesar $76 \%$ dengan kategori layak, dan dari indicator usability diperoleh hasil persentase sebesar $81 \%$ dengan kategori sangat layak[4].

Penelitian selanjutnya tentang pengukuran kualitas sistem informasi inventaris asset Universitas Muhammadiyah Bengkulu menggunakan metode McCall, dari penelitian ini dapat disimpulkan beberapa hal yaitu pada faktor kualitas corectness hasil pengukuran adalah sebesar $66 \%$ dan dalam kategori baik, pada Faktor usability hasil pengukuran adalah sebesar 58\% dan masuk dalam kategori cukup baik, pada faktor integrity hasil pengukuran adalah sebesar 42,2\% dan masuk dalam kategori yang cukup baik, pada faktor reliability hasil pengukuran yang diperoleh sebesar 49,2\% dan masuk dalam kategori cukup baik, pada faktor efficiency hasil pengukuran yang didapat sebesar $81 \%$ dan masuk dalam kategori sangat baik[5].

Penelitian lainnya melakukan analisis kualitas Sistem Informasi Unikom, dari penelitian ini dapat disimpulkan bahwa UNIKOM tidak memiliki tim SQA yang independen untuk menjamin kualitas setiap perangkat lunak, penerapan SQA di UNIKOM sangat berbeda dengan konsep kualitas perangkat lunak yang ada. [6]

Penelitian tentang penilaian kualitas usability e-learning menggunakan metode McCall menyimpulkan hasil analisis yang diperoleh pada studi kasus yaitu pada sistem e-learning STMIK AKAKOM Yogyakarta yaitu SIAKAD yaitu : kualitas usability perangkat lunak $=76,04 \%$, dan nilai masing - masing komponen kriteria diperoleh : correctness 14,48\%, Reliability 14,96\%, Efficiency 15,62\%, Usability $15,7 \%$, Maintainability $15,28 \%$, dan usability pada sistem e-learning $=77,37 \%$ berdasarkan bobot nilai yang digunakan maka masuk pada kategori "Cukup Baik" secara keseluruhan, untuk komponen Konten / Materi $=21 \%$, Komunikasi, Kerjasama, Interaksi $=20,43 \%$, Assessment $=21,36$, Fleksibilitas dan Adaptabilitas $=21,76 \%$, Dukungan mahasiswa, dosen, dan staff $=15,33 \%$. [7] 
Berkaitan dengan uraian diatas maka pada artikel ini peneliti akan membahas tentang pengukuran kualitas perangkat lunak dengan menggunakan faktor kualitas McCall yaitu kebenaran, kehandalan, efisiensi dan kegunaan pada aplikasi rekap indikator mutu harian.

\section{Metodologi}

Untuk membantu dalam penyusunan penelitian ini, maka perlu adanya susunan kerangka kerja yang jelas tahapan-tahapannya. Kerangka kerja ini merupakan langkah-langkah yang akan dilakukan dalam penyelesaian masalah yang akan dibahas. Adapun kerangka kerja penelitian yang digunakan adalah sebagai berikut:

1. Analisis permasalahanyang terjadi pada aplikasi rekap indikator mutu harian RS Bhayangkara Jambi terkini.

2. Studi literatur dilakukan dengan mempelajari dan memahami teori-teori yang menjadi pedoman dan referensi guna penyelesaian masalah dan mempelajari penelitian yang relevan dengan masalah yang diteliti.

3. Pengumpulan data berupa:

a. Pengamatan (Observation) terhadap proses penginputan indikator mutu harian yang berlangsung pada RS Bhayangkara Jambi dengan tujuan memperoleh informasi yang berkaitan dengan objek yang diteliti.

b. Wawancara (Interview) langsung dengan pihak RS Bhayangkara Jambi guna memperoleh informasi terkait indikator mutu harian yang selama ini berlangsung.

c. Kuesioner yang disusun untuk untuk mengetahui tingkat kualitas aplikasi rekap indikator mutu harian pada RS Bhayangkara Jambi. Instrument kuesioner yang digunakan adalah skala likert.

4. Pengukuran aplikasi rekap indikator mutu harian menggunakan metode McCall.

5. Pengolahan dan analisis data dengan melakukan perhitungan dan rekapitulasi hasil rata-rata nilai uji atas aplikasi rekap indikator mutu harian RS Bhayangkara Jambi berdasarkan beberapa faktor kualitas yang ada pada metode McCall yaitu product operations meliputi correctness, reliability, usability, dan efficiency.

6. Penarikan kesimpulan dan memberikan rekomendasi berupa saran kepada institusi untuk melakukan perbaikan kedepannya.

\section{Hasil dan Pembahasan}

Tampilan aplikasi rekap indikator mutu harian, dapat dilihat pada gambar berikut ini :

1. Halaman Login

Halaman Login menampilkan form yang berisikan field username dan password yang harus diisi untuk masuk kedalam system.

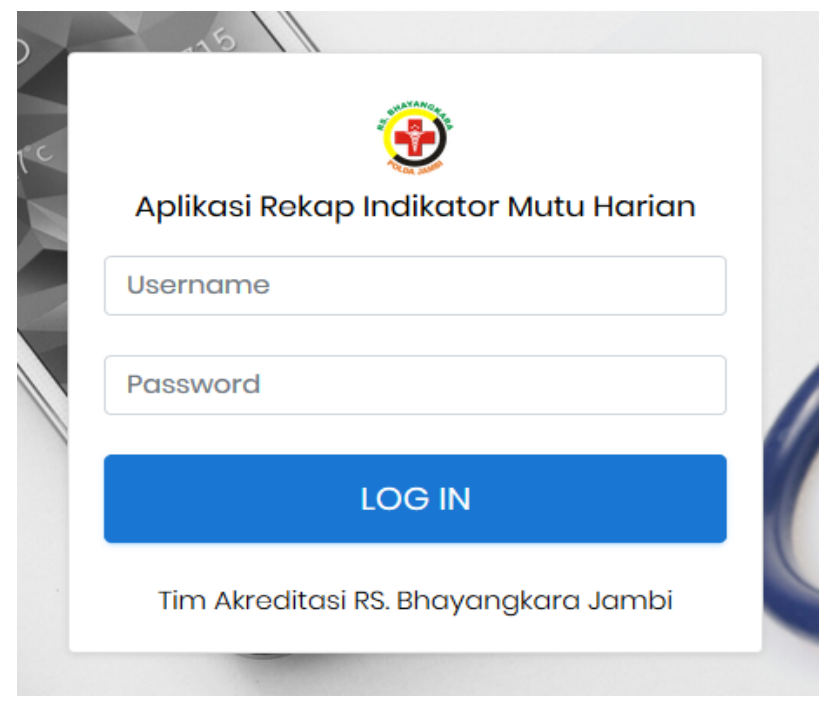

Gambar 1. Tampilan Halaman Login Pengguna 
2. Halaman Dashboard

Halaman dashboard menampilkan informasi statistik jumlah indikator mutu harian dan semua menu yang ada di aplikasi.

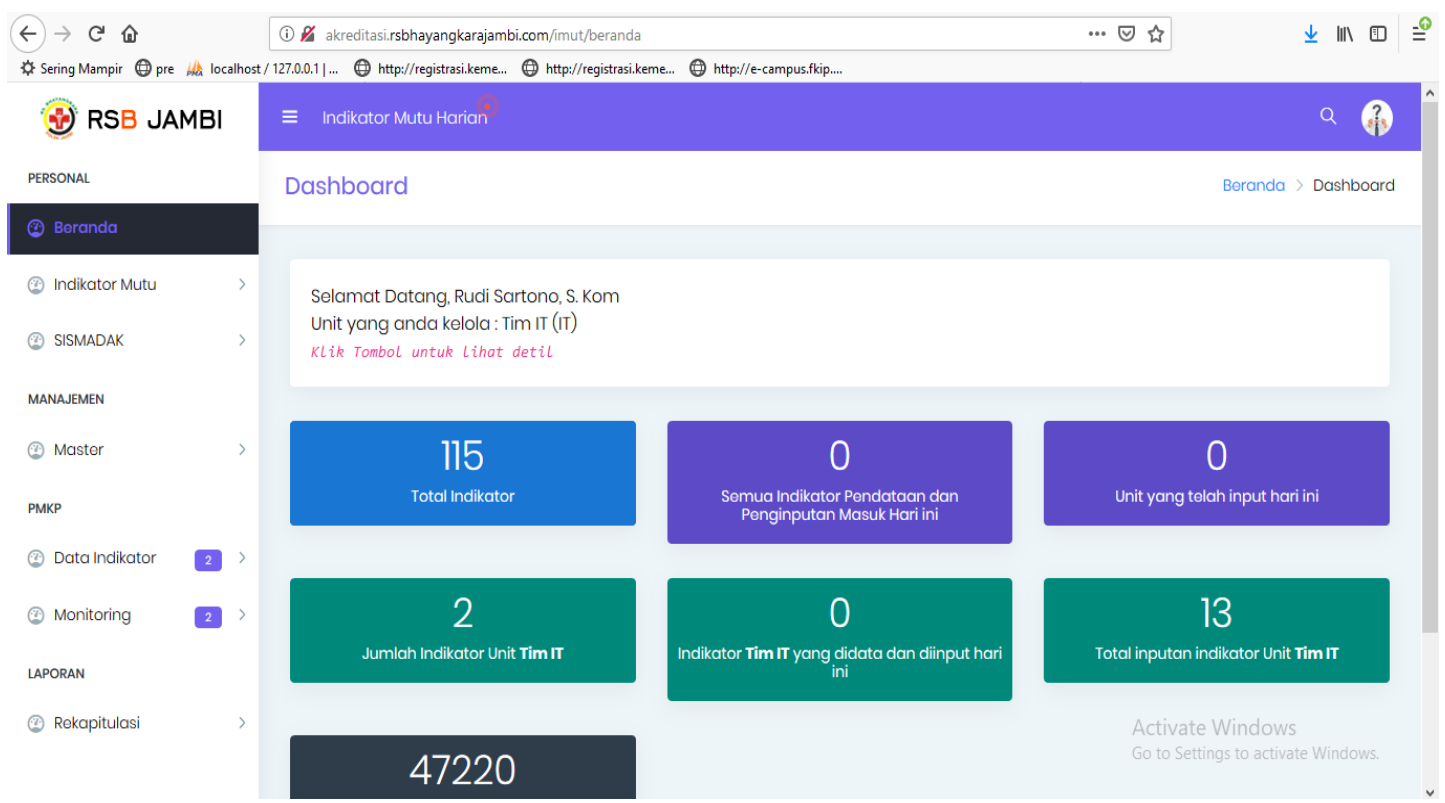

Gambar 2. Tampilan Dashboard

3. Halaman indikator mutu

Halaman indikator mutu menampilkan daftar indikator yang sedang digunakan oleh suatu unit.

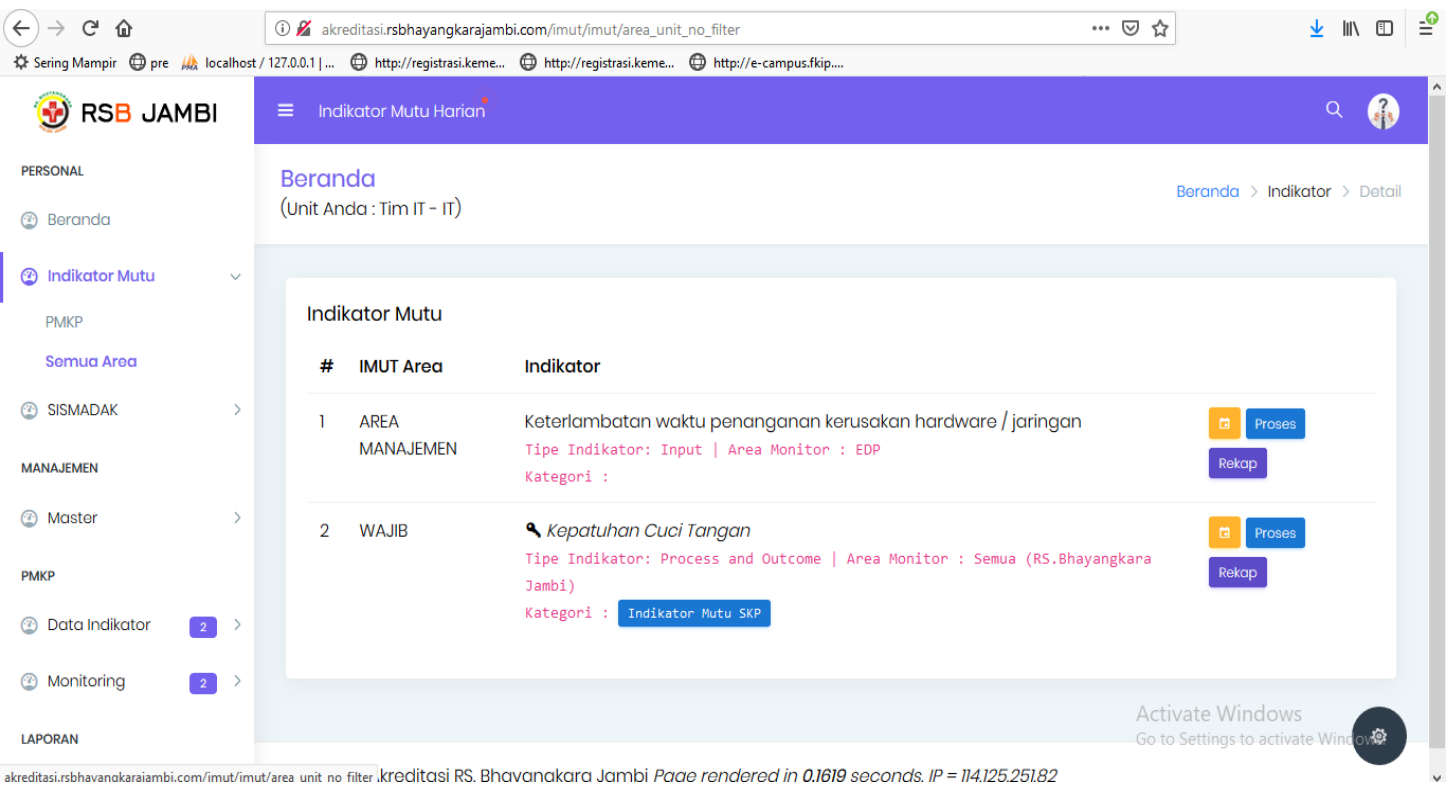

Gambar 3. Tampilan Halaman Indikator Mutu

4. Halaman Indikator Mutu Nasional dan Prioritas Rumah Sakit

Halaman Indikator Mutu Nasional dan Prioritas Rumah Sakit menampilkan indikator mutu nasional dan prioritas rumah sakit yang diwajibkan oleh Kemenkes. 


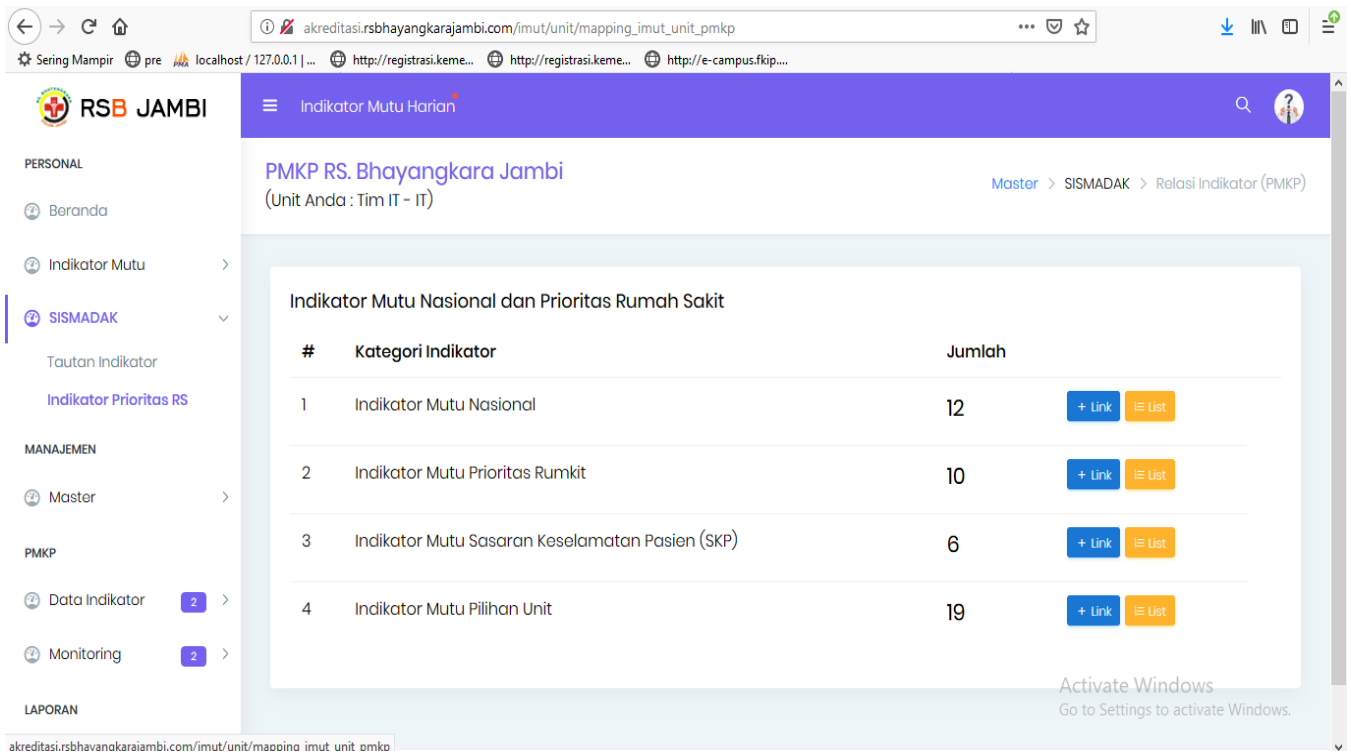

Gambar 4 Tampilan Halaman Indikator Mutu Nasional dan Prioritas Rumah Sakit

5. Halaman Monitoring Bulanan Indikator Mutu

Halaman ini menampilkan data rekapitulasi pengisian indikator mutu secara bulanan, halaman ini berisi beberapa kategori yang didalamnya terdapat field untuk memilih jenis indikator mutu dan memilih bulan serta tombol untuk melihat laporan bulanan.

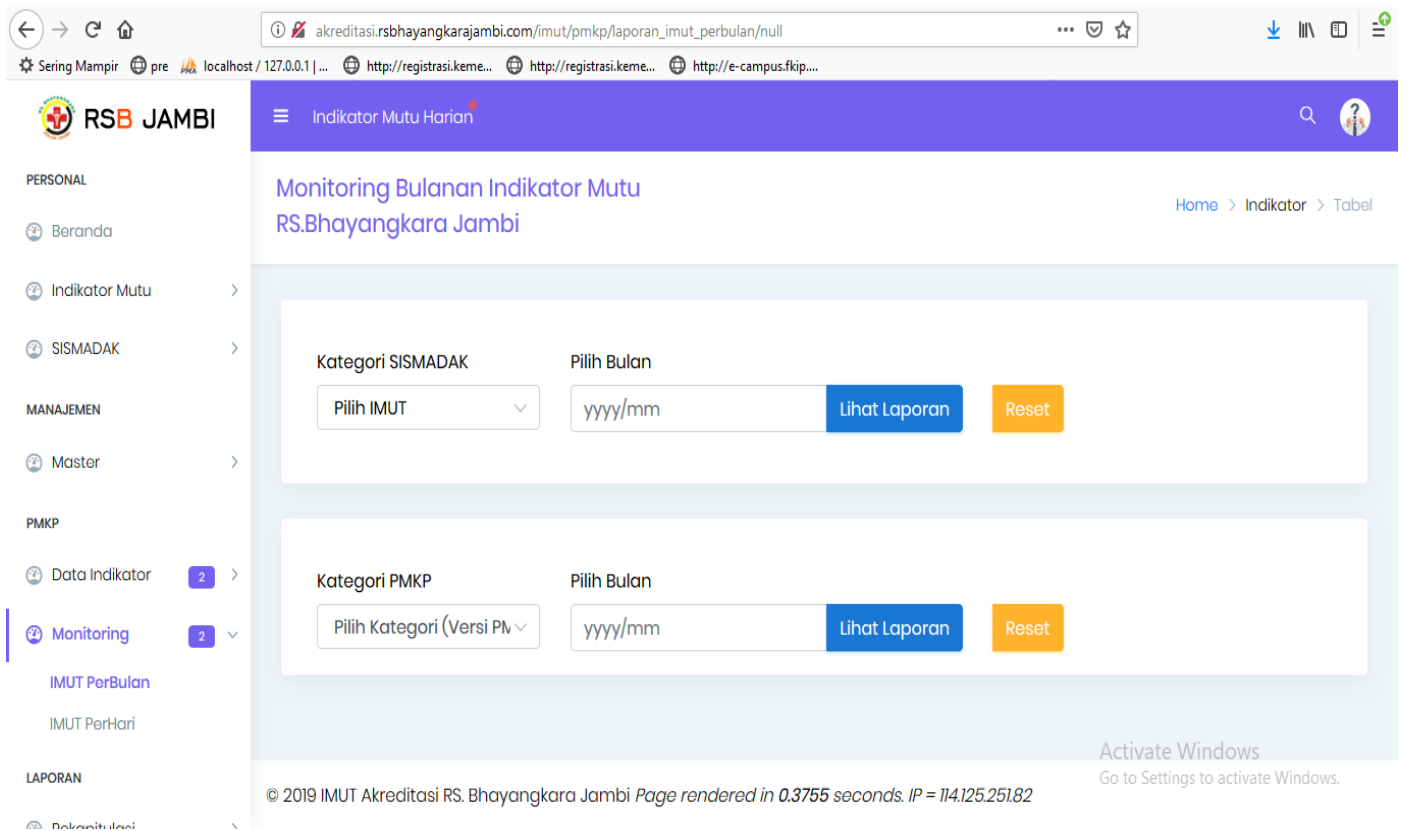

Gambar 5 Tampilan Halaman Monitoring Bulanan indikator Mutu 
6. Halaman Rekapitulasi

Halaman ini menampilkan data rekapitulasi pengisian indikator mutu secara harian.

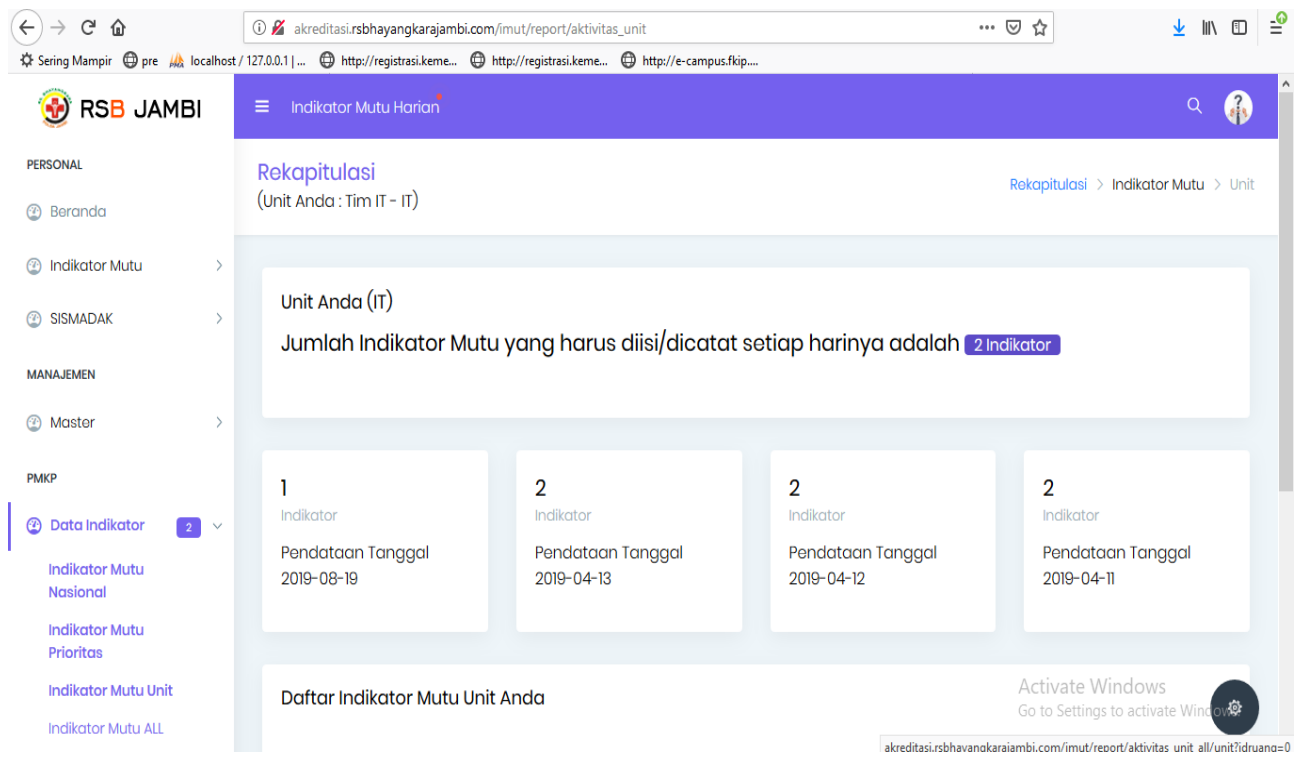

Gambar 6 Tampilan Halaman Rekapitulasi

Dalam melakukan penelitian ini instrument yang digunakan adalah berupa kuesioner. Teknik pengumpulan data ini bertujuan untuk memberikan jawaban dari opini pengguna (user) selama menggunakan aplikasi rekap indikator mutu harian di RS Bhayangkara Jambi. Untuk menentukan suatu jaminan kualitas perangkat lunak atau nilai kelayakan dari aplikasi rekap indikator mutu, instrument kuesioner yang digunakan adalah skala likert.

Dalam kuesioner yang digunakan untuk menentukan suatu jaminan kualitas perangkat lunak atau nilai kelayakan dari aplikasi rekap indikator mutu diberikan beberapa pertanyaan kepada pengguna (user) aplikasi rekap indikator mutu harian berdasarkan kriteria faktor kualitas yang ada pada metode McCall antara lain: correctness, reliability, usability, dan efficiency. Pengukuran dengan menggunakan skala likert ini akan diberikan nilai atau bobot tertentu pada setiap jawaban pertanyaan. Dalam penelitian ini skor atas skala likert yang digunakan adalah antara 1 sampai dengan 5 dengan 5 alternatif jawaban. Skala pengukuran kuesioner yang ditentukan dapat dilihat pada tabel berikut ini: [8]

Tabel 1. Tabel Skala Likert

\begin{tabular}{ll}
\hline Pernyataan Positif & Skor \\
\hline Sangat Setuju (SS) & 5 \\
Setuju (S) & 4 \\
Netral (N) & 3 \\
Kurang Setuju (KS) & 2 \\
Sangat Kurang Setuju (SKS) & 1 \\
\hline
\end{tabular}

Setelah ditentukan skala yang digunakan maka dibuat instrument pertanyaan berdasarkan teori McCall. Analisis data dilakukan dengan analisis data secara kuantitatif dengan menggunakan teknik pengukuran berdasarkan rumus: [9]

$\mathrm{Fa}=\mathrm{w} 1 \mathrm{c} 1+\mathrm{w} 2 \mathrm{c} 2+\mathrm{w} 3 \mathrm{c} 3+\ldots . .+\mathrm{wn} \mathrm{cn}$

Fa adalah faktor software quality, w1 adalah bobot yang bergantung pada produk dan kepentingan, c1 adalah metrik yang mempengaruhi faktor software quality.

Sistem penilaian menggunakan tahapan sebagai berikut: 
1. Menentukan kriteria yang digunakan untuk mengukur suatu faktor

2. Menentukan bobot $(\mathrm{w})$ dari setiap kriteria $(0,1<=\mathrm{w}<=0,4)$, berdasarkan kepentingan dari pimpinan Universitas terhadap sistem tersebut. dimana:

$0,1=$ sangat tidak penting,

$0,2=$ tidak penting,

$0,3=$ penting,

$0,4=$ sangat penting

3. Menentukan skala nilai kriteria, dimana skala penilaian yang digunakan antara 1 - 5, dengan ketentuan seperti disebutkan pada tabel 1.

4. Memasukkan nilai pada tiap kriteria

5. Menghitung nilai total dengan rumus: $\mathrm{Fa}=\mathrm{w} 1 \mathrm{c} 1+\mathrm{w} 2 \mathrm{c} 2+\ldots .+\mathrm{wncn}$

$\mathrm{Fa}$ adalah nilai total dari faktor a,

w1 adalah bobot untuk kriteria 1, dan c1 adalah nilai untuk kriteria 1

6. Kemudian nilai quality faktor diubah dalam bentuk persentase (\%). Besarnya persentase dihitung dengan menggunakan persamaan berikut:

$$
\text { Persentase }=\frac{\text { nillai yang didapat }}{\text { nilai maksimum }} \times 100 \% \ldots
$$

Selanjutnya, dari lima kategori yang ada di Tabel 1. dibuat skala menurut Arikunto, pembagian skala ini dilakukan dengan memperhatikan letak rentang bilangan. Sehingga pada Kondisi maksimal yang diharapkan adalah 100\%. Dari kondisi maksimal tersebut dibuat agar tiap kategori memiliki rentang persentase Antara nilai 1\% sampai dengan nilai $100 \%$ dibagi rata sehingga menghasilkan kategori kelayakan sistem seperti tabel berikut: [10]

Tabel 2. Tabel Kategori Kelayakan Sistem

\begin{tabular}{ll}
\hline Kategori & $\begin{array}{l}\text { Skor dalam } \\
\text { Persentase }\end{array}$ \\
\hline Sangat Layak & $81 \%-100 \%$ \\
Layak & $61 \%-80 \%$ \\
Cukup Layak & $41 \%-60 \%$ \\
Tidak Layak & $21 \%-40 \%$ \\
Sangat Tidak Layak & $<20 \%$ \\
\hline
\end{tabular}

Dengan menentukan nilai rata-rata pada tiap kriteria dan bobot yang bergantung pada kepentingan maka hasil penilaian kualitas perangkat lunak yang diperoleh dari 20 responden dapat dilihat pada tabel 3 berikut ini:

Tabel 3. Hasil Penilaian Kualitas Perangkat Lunak

\begin{tabular}{|c|c|c|c|c|}
\hline No & Indikator & Keterangan & Bobot & $\begin{array}{l}\text { Nilai } \\
\text { Kriteria }\end{array}$ \\
\hline \multirow[t]{8}{*}{1.} & $\begin{array}{l}\text { Correctness } \\
\text { (Ketepatan) }\end{array}$ & $\begin{array}{l}\text { a. Completeness (kelengkapan) } \\
\text { 1. Aplikasi ini sudah mampu melakukan proses pengolahan } \\
\text { data }\end{array}$ & 0,3 & 4,3 \\
\hline & & $\begin{array}{l}\text { 2. Fitur-fitur yang terdapat pada aplikasi rekap indikator mutu } \\
\text { harian sudah berfungsi semua }\end{array}$ & 0,4 & 3,7 \\
\hline & & b. Consistency (konsistensi) & & \\
\hline & & 1. Fitur dan desain tabel di setiap halaman sama & 0,3 & 4,5 \\
\hline & & 2. Fitur desain form dan tombol di setiap halaman sama & 0,3 & 4,3 \\
\hline & & 3.Pengelolaan data di setiap form sama & 0,4 & 4,5 \\
\hline & & $\begin{array}{l}\text { 4.Bahasa yang digunakan sudah konsisten pada setiap } \\
\text { halamannya }\end{array}$ & 0,4 & 4,5 \\
\hline & & $\begin{array}{l}\text { 5. Bentuk dan struktur pelaporan pengolahan semua data } \\
\text { sama }\end{array}$ & 0,3 & 4,4 \\
\hline
\end{tabular}




\begin{tabular}{|c|c|c|c|c|}
\hline & & $\begin{array}{l}\text { c. Treaceability (lacak) } \\
\text { Pengguna dapat melacak kapan waktu (tanggal dan jam) } \\
\text { penginputan indikator mutu harian }\end{array}$ & 0,4 & 4,3 \\
\hline \multirow[t]{12}{*}{2.} & \multirow{12}{*}{$\begin{array}{l}\text { Usability } \\
\text { (Kegunaan) }\end{array}$} & d. Communicativeness (komunikatif) & & \\
\hline & & 1. Bahasa yang digunakan mudah dipahami & 0,3 & 4,3 \\
\hline & & 2. Tulisan dari setiap halaman dapat terbaca dengan jelas & 0,3 & 4,4 \\
\hline & & 3. Fungsi dari setiap tombol jelas & 0,3 & 5 \\
\hline & & e. Operability (operabilitas) & & \\
\hline & & 1.Pilihan menu dan tombol pada system mudah digunakan & 0,3 & 4,5 \\
\hline & & $\begin{array}{l}\text { 2.Pengguna mudah mengerti dengan sistem pengkodean } \\
\text { yang ada }\end{array}$ & 0,2 & 2,5 \\
\hline & & f. Training (pelatihan) & & \\
\hline & & $\begin{array}{l}\text { 1. Pengguna baru dapat dengan mudah menggunakan } \\
\text { aplikasi rekap indikator mutu harian tersebut }\end{array}$ & 0,3 & 2,5 \\
\hline & & $\begin{array}{l}\text { 2.Ada layanan petunjuk (help) yang disediakan oleh } \\
\text { sistem guna membantu pengguna baru dalam } \\
\text { menggunakan aplikasi rekap indikator mutu harian }\end{array}$ & 0,3 & 4,3 \\
\hline & & $\begin{array}{l}\text { g. Security (keamanan) } \\
\text { 1. Proses log in dapat berjalan dengan benar dan sesuai } \\
\text { dengan harapan pengguna }\end{array}$ & 0,4 & 3,7 \\
\hline & & $\begin{array}{l}\text { 2. Aplikasi ini dapat mengontrol akses pengguna dengan } \\
\text { membatasi hak akses. }\end{array}$ & 0,4 & 4,5 \\
\hline \multirow[t]{10}{*}{3.} & \multirow{10}{*}{$\begin{array}{l}\text { Reliability } \\
\text { (Kehandalan } \\
\text { ) }\end{array}$} & h. Accuracy (akurasi) & & \\
\hline & & $\begin{array}{l}\text { 1. Aplikasi mudah memasukkan input yang diperlukan oleh } \\
\text { sistem. }\end{array}$ & 0,4 & 5 \\
\hline & & $\begin{array}{l}\text { 2. Aplikasi ini dapat menampilkan data yang tepat sesuai } \\
\text { dengan kata kunci yang dicari }\end{array}$ & 0,4 & 4,5 \\
\hline & & $\begin{array}{l}\text { 3. Aplikasi ini memberikan data dan informasi yang sesuai } \\
\text { dengan kebutuhan pengguna secara tepat }\end{array}$ & 0,4 & 4,5 \\
\hline & & 4. Informasi dari aplikasi ini akurat dan bebas dari kesalahan & 0,4 & 3,7 \\
\hline & & $\begin{array}{l}\text { 5. Pengguna dapat memperoleh informasi yang dibutuhkan } \\
\text { dalam waktu yang tepat }\end{array}$ & 0,4 & 4,3 \\
\hline & & $\begin{array}{l}\text { 6. Output dari aplikasi ini disajikan dalam bentuk yang tepat } \\
\text { sehingga memudahkan pemahaman pengguna }\end{array}$ & 0,4 & 3 \\
\hline & & $\begin{array}{l}\text { i. Error Tolerancy (toleransi kesalahan) } \\
\text { 1. Bagaimana jika akses ke aplikasi dan data tidak bisa } \\
\text { dipergunakan oleh pihak yang tidak berhak untuk } \\
\text { menggunakannya }\end{array}$ & 0,4 & 3,6 \\
\hline & & $\begin{array}{l}\text { j. Simplicity } \\
\text { 1. Informasi yang ada pada aplikasi ini mudah dipahami } \\
\text { tanpa ada kesulitan }\end{array}$ & 0,3 & 2,5 \\
\hline & & $\begin{array}{l}\text { 2. Menu-menu yang ada pada aplikasi ini dapat mudah } \\
\text { dipahami tanpa ada kesulitan }\end{array}$ & 0,3 & 3,7 \\
\hline \multirow[t]{4}{*}{4.} & \multirow{4}{*}{$\begin{array}{l}\text { Efficiency } \\
\text { (Efisiensi) }\end{array}$} & k. Execution Effiency (kemudahan eksekusi) & & \\
\hline & & $\begin{array}{l}\text { 1. Apakah menu layanan fungsi dan datanya sudah sesuai } \\
\text { dengan kebutuhan }\end{array}$ & 0,4 & 4,3 \\
\hline & & $\begin{array}{l}\text { 2. Interface, protokol yang digunakan untuk mengoperasikan } \\
\text { aplikasi rekap indikator mutu harian sudah memadai }\end{array}$ & 0,3 & 3,6 \\
\hline & & $\begin{array}{l}\text { 3. Fungsi dari konten atau isi yang ada didalam aplikasi } \\
\text { rekap indikator mutu harian sudah mengakomodasi } \\
\text { penyampaian informasi dari pihak rumah sakit }\end{array}$ & 0,3 & 4,5 \\
\hline
\end{tabular}

Langkah berikutnya setelah nilai pembobotan dan nilai kriteria ditentukan yaitu menentukan nilai totalnya Fa berdasarkan pada faktor kualitas yang ada pada McCall. Perhitungan masing-masing faktor kualitas dilakukan berdasarkan kriteria yang ditentukan adalah sebagai berikut: 
a. Correctness

Completeness $=\mathrm{w} 1 \mathrm{c} 1+\mathrm{w} 2 \mathrm{c} 2$

$$
\begin{aligned}
& =(0,3 \times 4,3)+(0,4 \times 3,7) \\
& =1,29+1,48 \\
& =2,77
\end{aligned}
$$

Consistency $=\mathrm{w} 1 \mathrm{c} 1+\mathrm{w} 2 \mathrm{c} 2+\mathrm{w} 3 \mathrm{c} 3+\mathrm{w} 4 \mathrm{c} 4+\mathrm{w} 5 \mathrm{c} 5$

$$
\begin{aligned}
& =(0,3 \times 4,5)+(0,3 \times 4,3)+(0,4 \times 4,5)+(0,4 \times 4,5)+(0,3 \times 4,4) \\
& =1,35+1,29+1,8+1,8+1,32 \\
& =7,56
\end{aligned}
$$

$$
\begin{aligned}
\text { Traceability } & =\mathrm{w} 1 \mathrm{c} 1 \\
& =(0,4 \mathrm{x} 4,3) \\
& =1,72
\end{aligned}
$$

$$
\begin{aligned}
\text { Fa } 1 & =\frac{\text { Completeness }+ \text { Consistency }+ \text { Treaceability }}{3} \\
\text { Fa } 1 & =\frac{2,77+7,56+1,72}{3} \\
& =4,02
\end{aligned}
$$

Persentase $=\frac{\text { nillai yang didapat }}{\text { nillai maksimum }} \times 100 \% \ldots$

Persentase $=\frac{4,02}{5} \times 100 \% \ldots$

$$
=80,4 \%
$$

b. Usability

Comunicativeness $=\mathrm{w} 1 \mathrm{c} 1+\mathrm{w} 2 \mathrm{c} 2+\mathrm{w} 3 \mathrm{c} 3$

$$
\begin{aligned}
& =(0,3 \times 4,3)+(0,3 \times 4,4)+(0,3 \times 5) \\
& =1,29+1,32+1,5 \\
& =4,11
\end{aligned}
$$

$$
\begin{aligned}
\text { Operability } & =\mathrm{w} 1 \mathrm{c} 1+\mathrm{w} 2 \mathrm{c} 2 \\
& =(0,3 \times 4,5)+(0,2 \times 2,5) \\
& =1,35+0,5 \\
& =1,85
\end{aligned}
$$

Training $=\mathrm{w} 1 \mathrm{c} 1+\mathrm{w} 2 \mathrm{c} 2$

$$
\begin{aligned}
& =(0,3 \times 2,5)+(0,3 \times 4,3) \\
& =0,75+1,29 \\
& =2,04
\end{aligned}
$$

Security $=\mathrm{w} 1 \mathrm{c} 1+\mathrm{w} 2 \mathrm{c} 2$

$$
\begin{aligned}
& =(0,4 \times 3,7)+(0,4 \times 4,5) \\
& =1,48+1,8 \\
& =3,28
\end{aligned}
$$

$$
\begin{aligned}
\mathrm{Fa} 2 & =\frac{\text { Communicativeness }+ \text { Openability }+ \text { Training }+ \text { Security }}{4} \\
\mathrm{Fa} 2 & =\frac{4,11+1,85+2,04+3,28}{4} \\
& =2,82
\end{aligned}
$$




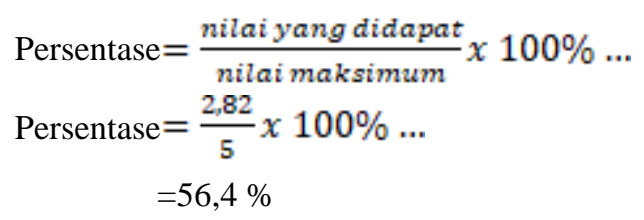

c. Reliability
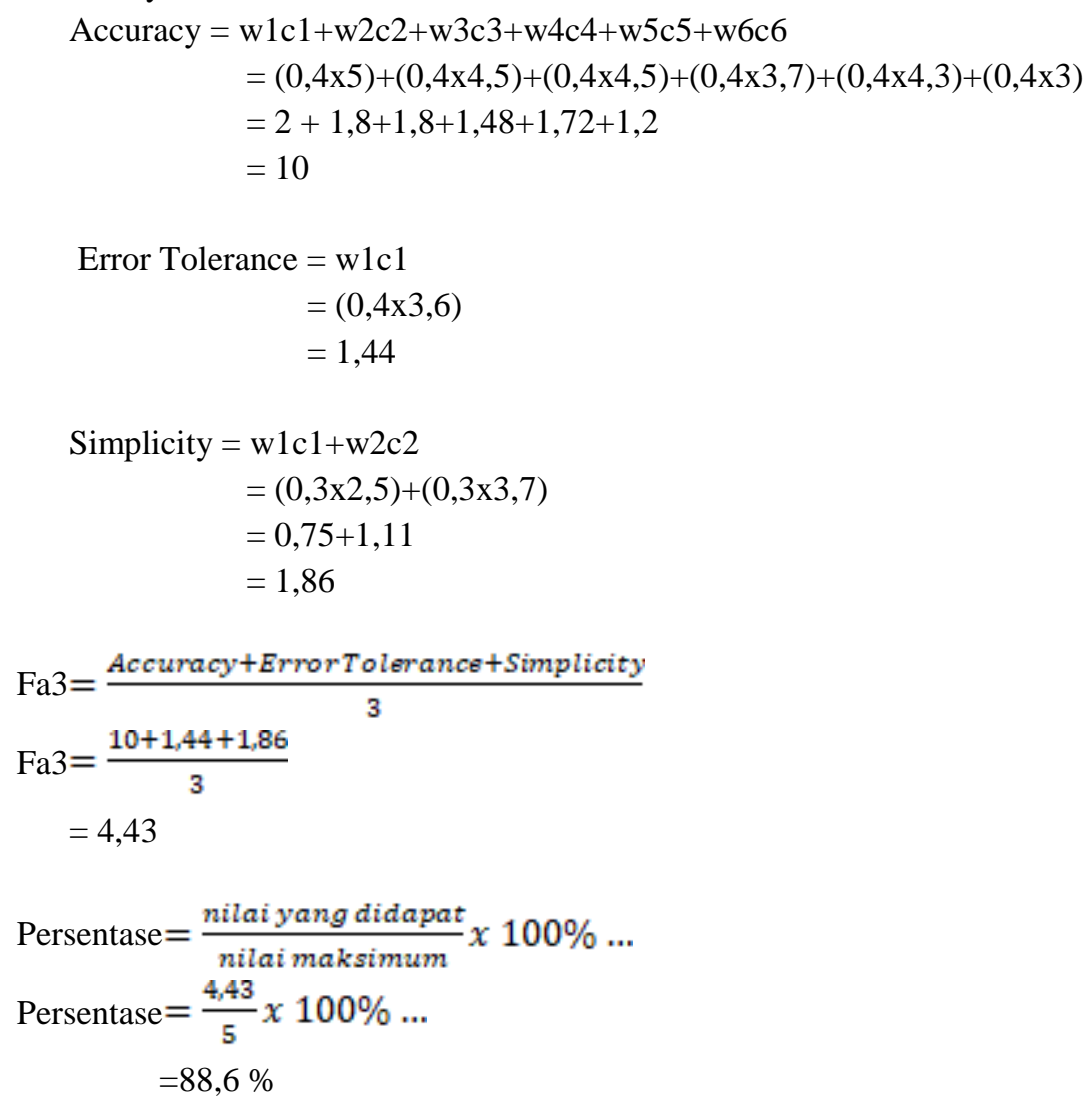

d. Efficiency

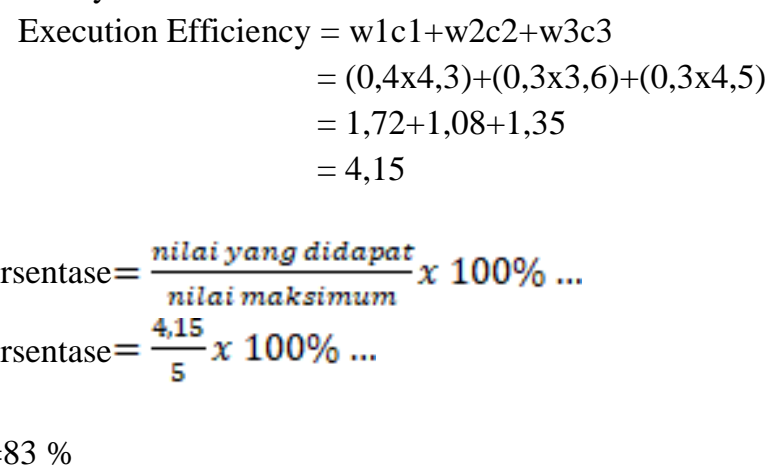

Dari hasil perhitungan diatas diperoleh nilai masing-masing komponen kriteria yaitu: correctness $80.4 \%$, usability $56.4 \%$, reliability $88.6 \%$ dan efficiency $83 \%$. Berdasarkan ketentuan yang ada hasil pengukuran kualitas pada reliability merupakan nilai yang tertinggi dan masuk dalam kategori sangat layak untuk digunakan, sedangkan pada usability mendapatkan nilai yang terendah dan masuk kedalam kategori cukup layak untuk digunakan, sehingga untuk upaya pengembangan dapat ditingkatkan pada sisi usability atau kegunaan pada aplikasi rekap indikator mutu harian. Dari segi kehandalan aplikasi ini sudah sangat layak untuk digunakan akan tetapi perlu dilakukan sosialisasi berupa pelatihan penggunaan aplikasi pada user sehingga user dapat mengetahui berbagai fitur yang ada di aplikasi tersebut. 


\section{Kesimpulan}

Berdasarkan hasil analisis data hasil pengukuran kualitas terhadap aplikasi rekap indikator mutu harian di RS Bhayangkara Jambi maka diperoleh pada faktor kualitas correctness hasil pengukuran adalah sebesar 80,4 \% dan dalam kategori layak. Pada faktor kualitas usability hasil pengukuran adalah sebesar 56,4 \% dan masuk dalam kategori cukup layak. Pada faktor kualitas reliability hasil pengukuran yang diperoleh adalah sebesar $88,6 \%$ dan masuk dalam kategori sangat layak. Sedangkan pada faktor kualitas efficiency hasil pengukuran yang diperoleh adalah sebesar $83 \%$ dan masuk dalam kategori sangat layak. Berdasarkan hasil tersebut aplikasi rekap indikator mutu harian ini sudah layak untuk digunakan dan memiliki fitur yang lengkap sesuai dengan kebutuhan rekapitulasi pada umumnya, akan tetapi perlu dilakukannya sosialisasi berupa pelatihan penggunaan aplikasi agar para user tidak kesulitan dalam penggunaannya serta diadakan pengukuran untuk semua faktor kualitas yang ada pada metode McCall yang terdiri dari 11 faktor kualitas agar pengembang dapat mengetahui kekurangan aplikasi dari berbagai sisi. Saran yang dapat peneliti berikan dari hasil penelitian yang dilakukan menunjukan beberapa hal yang perlu ditingkatkan lagi yaitu dari sisi kualitas usabilitas aplikasi rekap indikator mutu harian sehingga aplikasi ini akan memiliki nilai guna yang tinggi. Selain itu perlu dilakukan analisis pengukuran kualitas dengan metode lain sehingga dapat digunakan sebagai pembanding.

\section{Daftar Rujukan}

[1] A. W. Budyastomo, B. S. L. Saputro, and K. C. Rukma, "Pengujian Kualitas Sistem Pakar Deteksi Kerusakkan Mesin Sepeda Motor Non Matic dengan Menggunakan Metode McCall," Semin. Nas. IENACO, no. ISSN 2337-4349, pp. 141-146, 2014.

[2] N. M. S. Iswari, "Review Perangkat Lunak StarUML Berdasarkan Faktor Kualitas McCall," Ultimatics, vol. VII, no. 1, pp. 72-81, 2015.

[3] H. T. Hidayat, "Uji Kelayakan Sistem Informasi Akademik Menggunakan Faktor Kualitas McCall A-34 A-35," vol. 2, no. 1, pp. 34-38, 2018.

[4] D. P. Mandala, "Uji Kelayakan Sistem Informasi Unit Kesehatan Sekolah Berbasis Website Di Smk Muhammadiyah 1 Bantul Dengan Faktor Kualitas Mccall," Elinvo (Electronics, Informatics, Vocat. Educ., vol. 2, no. 2, pp. 195-203, 2017, doi: 10.21831/elinvo.v2i2.17314.

[5] Khairullah, B. Soedijono, and H. Al Fatta, "Pengukuran Kualitas Sistem Informasi Inventaris Aset Universitas Muhammadiyah Bengkulu Menggunakan Metode MCCALL," Inf. Interaktif, vol. 2, no. 2, pp. 84-92, 2017.

[6] A. M. Bachtiar, D. Dharmayanti, M. K. Sabariah, A. M. Bachtiar, D. Dharmayanti, and M. K. S, "Analisis Kualitas Perangkat Lunak Terhadap Sistem Informasi Unikom," vol. 11, no. 2, pp. 224233, 2007.

[7] E. Susanti, "Penilaian Kualitas Usability e-Learning Menggunakan Metode McCall (Studi Kasus: STMIK AMIKOM Yogyakarta)," TEKINFO - J. Ilm. Tek. Ind. dan Inf., vol. 5, no. 2, pp. 65-93, 2017.

[8] Sugiyono, Metode Penelitian Kombinasi (Mixed Method), Alfabeta, Bandung, 2013.

[9] R. S. Wahono, Teknik Pengukuran Kualitas Perangkat Lunak, 2006 http://romisatriawahono.net/2006/06/05/teknik-pengukuran-kualitas perangkat-lunak. [Accessed 09 Oktober 2019].

[10] S. Arikunto, Manajemen Penelitian, PT. Rineka Cipta, Jakarta, 2009 